Review Article

\title{
A Review of Clinical Applications and Side Effects of Methotrexate in Ophthalmology
}

\author{
Ge Wang $(\mathbb{D}$ and Xiaoyan Peng $(\mathbb{D}$ \\ Beijing Institute of Ophthalmology, Beijing Tongren Eye Center, Beijing Tongren Hospital, Capital Medical University, \\ Beijing Ophthalmology and Visual Science Key Lab, Beijing, China
}

Correspondence should be addressed to Xiaoyan Peng; drpengxy@163.com

Received 13 April 2020; Revised 18 June 2020; Accepted 3 July 2020; Published 11 August 2020

Academic Editor: Enrico Peiretti

Copyright $(0) 2020$ Ge Wang and Xiaoyan Peng. This is an open access article distributed under the Creative Commons Attribution License, which permits unrestricted use, distribution, and reproduction in any medium, provided the original work is properly cited.

\begin{abstract}
Methotrexate (MTX) is a folate analog widely used against a range of diseases including malignancies and autoimmune disorders. Its high effectiveness-price ratio also won extensive application in ophthalmology. On the other hand, although MTX has an excellent pharmacological efficacy, MTX associated side effects in clinical use, which vary from patient to patient, are nonnegligible. There is no comparatively systematic review on MTX associated side effects and its risk factors. This review aimed to reveal novel clinical approaches of MTX and its adverse effects in order to provide a reference for ophthalmic scholars in clinical application of MTX.
\end{abstract}

\section{Introduction}

Methotrexate (MTX) is an antifolate metabolite that inhibits DNA synthesis, repair, and cellular replication. It was firstly used as one of the essential treatments of pediatric leukemia $[1,2]$. According to previous studies, MTX has also been used to treat rheumatoid arthritis (RA) and psoriasis as antiinflammatory and immunomodulatory agent [3], as MTX could not only optimize the efficacy of biological disease modifying antirheumatic drugs (DMARDs) $[4,5]$, but also make the therapeutic goals via lower doses in comparison with other conventional synthetic DMARDs [5]. Figure 1 shows the pathway of folate in DNA synthesis, the cellular pathway of MTX, and how MTX works inside the cell. While immediate and low-dose MTX is used to treat nonmalignant and immune-mediated disorders, high-dose MTX (HDMTX, more than $500 \mathrm{mg} / \mathrm{m}^{2} /$ week) is widely used to treat malignancies. Until now, HD-MTX (with or without radiation therapy) is still the backbone of most modern chemotherapy regimens [6], as well as the prevention of systemic/central nervous system (CNS) lymphoma recurrence at a dose of $3 \mathrm{~g} / \mathrm{m}^{2}$ per week [7].
MTX has also been widely applied in ophthalmic diseases, systemically and locally. Recently published articles pay more attention to new clinical applications, routes of administration, and newly discovered side effects, which are foci of this review.

\section{Clinical Applications in Ophthalmology}

As one of the known corticosteroids-sparing agents, MTX has been widely used in the treatment of anterior, intermediate, posterior, or pan uveitis; scleritis; and ocular mucous membrane pemphigoid [8], as well as advanced proliferative diabetic retinopathy [9]. However, followed researches reveal that MTX works with a significant difference in effectiveness ratings by anatomic location of inflammation [10], with treatment success achieved most commonly in patients with anterior uveitis and scleritis [11]. In the treatment of noninfectious intraocular inflammation, oral and intravenous are the most common routes with a usual dose range of $7.5 \mathrm{mg}$ to $25 \mathrm{mg}$ weekly. The typical dose observed was $12.5 \mathrm{mg} /$ week $[12,13]$, which is in the range of low-dose MTX. The median time to achieve the success of 


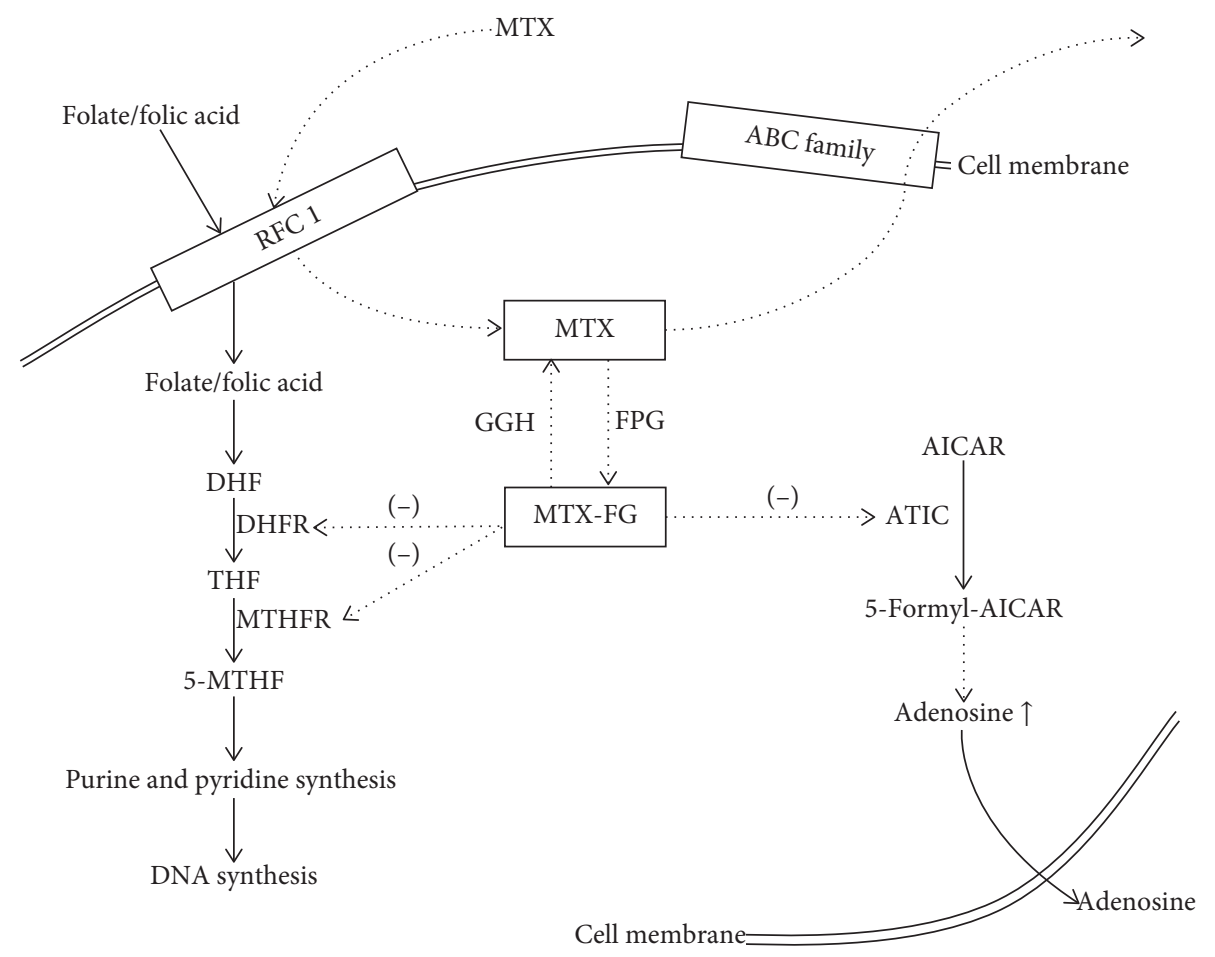

FIgURE 1: The cellular pathway of folate and MTX. Dietary folate enters the cells through RFC1, as well as MTX. In low-dose MTX treatment, MTX inhibits enzymes of the folate pathway. Ultimately, MTX leads to an increase in intracellular adenosine level, which would cause antiinflammatory effects. RFC-1 = reduced folate carrier 1 ; $A B C$ family = adenosine triphosphate-binding cassette $(\mathrm{ABC}) \mathrm{family}$; $\mathrm{DHF}=\mathrm{di}-$ hydrofolate; THF = tetrahydrofolate; $\mathrm{GGH}=\gamma$-glutamyl hydrolase; $\mathrm{FPG}=$ folylpolyglutamate synthase; $\mathrm{MTX}-\mathrm{PG}=$ methotrexate polyglutamate; DHFR = dihydrofolate reductase; MTHFR = methylene tetrahydrofolate reductase; AICAR=aminoimidazole carboxamide ribonucleotide; ATIC = AICAR transformylase.

treatment, defined as control of inflammation with the ability to taper corticosteroids to $10 \mathrm{mg}$ or less daily, ranges from 4.5 months to 9 months for MTX [14, 15].

Intravitreal MTX injection, with or without systemic chemotherapy and radiotherapy, has already been used to treat primary intraocular lymphoma patients [7, 16-19]. According to Larkin et al. [20], intravitreal MTX injection could achieve remission in a proportion of patients with primary intraocular lymphoma. What is particularly noteworthy is that although MTX has a slow rate of onset of effect, when it was used to treat intraocular lymphoma via intravitreal injection, it prolonged local remission of ocular disease even with an aggressively growing tumor [16]. Therefore, it has been taken as a relatively first-line choice for the treatment of recurrent intraocular lymphoma [17], although the treatment for primary intraocular lymphoma is lacking solid justification because of the limited retrospective and prospective case series [21]. Local treatment via intraocular injection provides a consistent therapeutic MTX concentration to reduce the systemic MTX associated side effects [19]. Therefore, intraocular MTX injection is worth trying, especially for unilateral ocular diseases.

\section{New Approaches of Applications of MTX}

3.1. MTX Used against Epithelial Downgrowth. Previous studies have already demonstrated safety of intravitreal
MTX [18]. It has been used to treat intraocular lymphoma and proliferative vitreoretinopathy because of its antiproliferative properties [22]. There is a novel use of intravitreal MTX for recurrent epithelial downgrowth which was not treated by surgical and medical methods. Lambert et al. [23] administered intravitreal MTX to patients with refractory proliferative membrane after cataract surgery, while membrane peel and endolaser treatment failed. The injection of MTX was administered alone, based on previous protocols and the presumed half-life of drugs in vitreous cavity. After 12 injections totally, there was no membrane recurrence. This case suggests that intravitreal MTX plays a role in treatment against epithelial downgrowth.

\subsection{MTX Used in Conventional Therapy-Resistant Diseases.} Generally, the antivascular endothelial growth factor (antiVEGF) therapy has dramatically improved the prognosis of neovascular age-related macular degeneration (nAMD). However, there are still some patients who remain refractory to anti-VEGF therapy, which is termed as treatment-resistant nAMD. As there is evidence that MTX has effects in interrupting the angiogenesis cascade at various levels [24], Kurup et al. offered intravitreal MTX to patients who were refractive to standard anti-VEGF therapy [25]. Although it was an off-label use, the patients' visual acuity improved at follow-up visit, while ophthalmic imaging examinations showed significantly reduced cystoid macular edema. Thus, 
patients who are refractory to traditional anti-VEGF therapy might benefit from intravitreal injection of MTX.

This approach is not alone. Khalil et al. [26] had $400 \mu \mathrm{g} / 0.1 \mathrm{ml}$ of MTX intravitreal injection once monthly administrated to 20 adult Behcet's disease (BD) patients suffering from $\mathrm{BD}$-associated ocular inflammation with posterior segment involvement. Their results prove that intravitreal MTX improves visual acuity, reduces posterior segment manifestations associated with Behcet's disease, and allows the reduction of corticosteroids and immunosuppressive drugs [26]. These results also supported Taylor and associates who conducted trials on 15 patients with unilateral uveitis and/or cystoid macular edema [27]. Their clinical trials suggest that intravitreal MTX may help patients with uveitis-associated posterior segment involvement to regain normal anatomical structure and then allowed the reduction of immunosuppressive therapy.

\section{The Pharmacogenetics of MTX}

With molecular sequencing and high-throughput technology, large numbers of genetic polymorphisms can now be detected accurately and rapidly [28]. Researchers pay more attention to pharmacogenetics, the study of genetic polymorphisms in drug-metabolizing enzymes and the translation of inherited differences to differences in drug effects [29]. The genes encoding transporting proteins and metabolizing enzymes for MTX are also known to harbor functionally significant SNPs. The SNPs may influence the efficacy of MTX and have been suggested as potential risk factors for enhanced MTX toxicity, even in low-dose regimens, based on previous researches [30].

The research of pharmacogenetics of MTX could be divided into genetic polymorphisms affecting MTX transport and SNPs that influence enzymes in the cellular pathway of MTX [29].

Once taken, MTX enters the cell through an active transport which is mediated by the reduced folate carrier 1 (RFC1). The loss of RFC1 gene expression might lead to effects of uptake and intracellular levels of MTX. A G80A SNP of RFC1 was proposed [31] making a decreasing [32] or increasing $[33,34]$ effect on intracellular level of MTX. Therefore, a significant association between RFC1 SNPs and MTX toxicity should be considered. Chango et al. state that these SNPs strongly impact the overall MTX associated side effects by resulting in altered cellular MTX concentration, but with no influence on MTX efficacy [35]. However, some researchers argue that these SNPs have no definite effect [36]. Thus, it remains controversial whether SNPs of RFC1 affect the transport of MTX. Moreover, P-glycoprotein, a membrane transporter that has influences on the disposition and bioavailability of MTX [37], was studied. SNPs of ABCB1, including C3435T SNP and C1236T SNP, were believed to have effects on the expression of P-glycoprotein [38]. Gervasini et al. speculate the C1236T SNP of ABCB1 affects the administered doses of MTX and the incidence of hematological toxicity [28]. However, just like G80A SNP, there are disputes about the influences of these SNPs, as different studies had different outcomes [29].
Metabolizing enzymes were also being analyzed, given the critical role of transporters in disposition of MTX and its active products, as well as the folate metabolism. MTX pharmacogenetics mostly focused on the SNPs in the MTHFR gene. The present study shows that genetic polymorphisms in the folate metabolic pathway and in MTX transporters influence the toxicity but not the efficacy of the low-dose MTX treatment in patients with autoimmune diseases [39]. For example, C677T and A1298C are known in MTHFR gene to result in a lower enzyme activity [39]. Windsor and associates reported that MTHFR A1298C and C677T were associated with MTX related nephrotoxicity and anemia [40]. These SNPs might be associated with decreased activity of methylenetetrahydrofolate reductase, elevated plasma homocysteine levels, and altered distribution of folate [41]. Thus patients with this genotype were more vulnerable to potential MTX induced toxicity since these reactions above may lead to slower folate metabolism and slower cell repair [42]. Weisman et al. used univariate logistic regression to reveal that the MTHFR C677T also increases the occurrence of side effects in central nervous system, manifested as headache and lethargy [43]. However, Lambrecht et al. argued that MTHFR C667T was not a predictive factor for toxicity [42]. Berkani et al. found no association between A1298C polymorphism and MTX toxicity [44]. Interestingly, Grabar et al. claimed that the patients with MTHFR 1298C genotype have a lower risk for MTX toxicity than the carriers of MTHFR 1298A allele [39].

To date, the study of pharmacogenetics of MTX continues. An increasing number of SNPs have been found to be possibly associated with the efficacy and toxicity of MTX. The newly discovered genotypes include C347G in ATIC and $5^{\prime}$-UTR 28-bp repeat and $3^{\prime}$-UTR 6-bp deletion in TYMS, which may influence both efficacy and toxicity of MTX; similarly, factors that may affect MTX associated toxicity are, for example, A2756G in MS and A66G in MTRR $[29,39,45,46]$. The genes and their SNPs that might be associated with the effects and side effects of MTX are summarized in Table 1. Growing evidences suggest that a single genetic factor is unlikely to adequately predict the efficacy and toxicity of MTX in polygenic disease, such as RA and autoimmune associated ocular disease. Given the impact of MTX in several metabolic pathways, a complex of multiple risk genotypes examination would help to predict the efficacy of MTX and to identify patients who may have adverse effects from MTX administration.

Taken together, the efficacy and toxicity of MTX may remain associated with the genetic markers in the patients. Therefore, although this remains a controversial subject, it is reasonable to believe that pharmacogenetics may be able to predict who is at risk of MTX associated adverse effects and may help in maximizing the benefit-risk ratio of MTX.

\section{The Side Effects of MTX}

The dose-limiting toxicity of MTX mainly includes hepatotoxicity and nephrotoxicity [56-59], but mortality has often been reported due to either pneumonitis or secondary infections [60]. 
TABLE 1: Summary of genes and their SNPs which might have possible clinical effects towards MTX.

\begin{tabular}{|c|c|c|c|c|}
\hline & & Gene & $\mathrm{SNP}(\mathrm{s})$ & Possible clinical effects \\
\hline \multirow{7}{*}{$\begin{array}{l}\text { Transporting } \\
\text { proteins }\end{array}$} & \multirow{7}{*}{$\begin{array}{l}\mathrm{ABC} \\
\text { family }\end{array}$} & $1[31-34]$ & G80A & \multirow{3}{*}{$\begin{array}{l}\text { Increasing/decreasing intracellular MTX level } \\
\text { Affecting efficacy of MTX } \\
\text { Affecting the distribution of MTX and incidence of hematological toxicity }\end{array}$} \\
\hline & & \multirow{2}{*}{$\begin{array}{c}\mathrm{ABCB} 1[28 \\
29,38]\end{array}$} & $\mathrm{C} 3435 \mathrm{~T}$ & \\
\hline & & & $\mathrm{C} 1236 \mathrm{~T}$ & \\
\hline & & $\mathrm{ABCC} 1[47$ & $\begin{array}{l}\mathrm{rs} 246240 \mathrm{~S} \\
\mathrm{rs} 3784862\end{array}$ & Association with MTX related toxicity \\
\hline & & \multirow{3}{*}{$\begin{array}{c}\text { ABCC2 }[29, \\
45]\end{array}$} & A2412G & \multirow{6}{*}{$\begin{array}{l}\text { Leading to accumulation of MTX to nephrotoxic levels } \\
\text { Association with MTX related gastrointestinal toxicity } \\
\text { Association with MTX related hepatotoxicity } \\
\text { Association with MTX related hematological toxicity } \\
\text { Affecting the toxicity but not the efficacy by resulting in a lower enzyme } \\
\text { activity; association with related nephrotoxicity, anemia, and neurologic } \\
\text { side effects }\end{array}$} \\
\hline & & & G1249A & \\
\hline & & & G1058A & \\
\hline \multirow{9}{*}{$\begin{array}{l}\text { Metabolizing } \\
\text { enzymes }\end{array}$} & & ABCC4 [28] & $\mathrm{C} 934 \mathrm{~A}$ & \\
\hline & \multirow{2}{*}{\multicolumn{2}{|c|}{ MTHFR [39-44] }} & C677T & \\
\hline & & & A1298C & \\
\hline & AT & $\mathrm{C}[49-51]$ & C347G & Affecting efficacy and toxicity of MTX \\
\hline & \multirow{2}{*}{\multicolumn{2}{|c|}{ TYMS $[52,53]$}} & $\begin{array}{l}5^{\prime} \text {-UTR } 28-b p \\
\text { repeat }\end{array}$ & Affecting efficacy and toxicity of MTX \\
\hline & & & $\begin{array}{c}3^{\prime} \text {-UTR 6-bp } \\
\text { deletion }\end{array}$ & Affecting efficacy of MTX. \\
\hline & \multicolumn{2}{|c|}{ GGH $[46,54,55]$} & $\begin{array}{l}\mathrm{C} 452 \mathrm{~T} \\
\mathrm{C} 401 \mathrm{~T}\end{array}$ & Affecting efficacy of MTX \\
\hline & \multicolumn{2}{|c|}{ DHFR $[29,45]$} & $\begin{array}{l}\mathrm{T} 721 \mathrm{~A} \\
\mathrm{C} 830 \mathrm{~T}\end{array}$ & Affecting efficacy of MTX \\
\hline & \multicolumn{2}{|c|}{$\begin{array}{l}\text { MS }[29,45,54] \\
\operatorname{MTRR}[29,45,51]\end{array}$} & $\begin{array}{l}\text { A2756G } \\
\text { A66G }\end{array}$ & $\begin{array}{l}\text { Association with MTX associated toxicity } \\
\text { Association with MTX associated toxicity }\end{array}$ \\
\hline
\end{tabular}

Some experts divided MTX associated pulmonary complications into inflammatory, infectious, and lymphoproliferative [61]. In the authors' opinion, all MTX related side effects can be classified into these three categories according to the pharmacological effects of MTX.

Major adverse events for MTX are related to the folate antagonism and primarily affect highly proliferative tissues such as bone marrow and gastrointestinal mucosa [62]. Given the immunosuppression effect of MTX, pancytopenia was one of the most frequent severe toxicities of methotrexate [30]. Meanwhile, the risk of developing an infectious process is increased all along the treatment, and the severity of the infected disease would be worsen $[63,64]$, including common bacterial infections, herpes zoster eruptions, and opportunistic infections. According to previous studies, the risk is larger than that with other disease modifying antirheumatic nonbiological drugs (DMARDs).

Secondly, the MTX acts as the hapten [65] and is likely to react directly with nucleophilic groups present in proteins, i.e., to combine with endogenous protein $[66,67]$. The protein adducts thus act as an antigenic signal to direct the effector arm of the immune response [68]. The provoked immune responses are most commonly type I (immediate hypersensitivity) and type III (immune complex) reactions [66]. Hypersensitivity pneumonitis is the most common, severe, and unpredictable complication, with a mortality of up to almost $25 \%$ [69].

Moreover, a few studies have shown that long-term MTX use can lead to lymphoproliferative disorders (LPDs) in both nodal sites and extra nodal sites, such as the skin, lungs, epipharynx, thyroid gland, nasal cavity, spleen, and kidneys, especially for patients who are positive for EBV infection [70-73]. The reported frequency of EBV positive in MTX associated LPDs patients is $27 \%-50 \%$ [74]. Although the mechanism of onset is not fully understood, it is believed that the combination of immunodeficiency and the immunosuppressive effect of MTX has been implicated in the pathogenesis of MTX associated LPDs. The World Health Organization (WHO) has classified MTX associated LPDs as lymphoid neoplasms, whether iatrogenic or immunodeficiency associated diseases [73, 75]. MTX associated LPDs often take a spontaneous remission, which tends to complete mostly within 4 weeks, after the discontinuation of MTX [74]. But there are a few reports showing that the lymphoid neoplasms occur even after stopping using MTX [76].

5.1. The Effects of Administration Routes. Generally, the side effects of MTX depend on the route of administration. Dosedependent [77] gastrointestinal side effects are the most frequent side events with orally administered MTX, as oral administration is the most common delivery method $[56,57,77,78]$. More than $90 \%$ of MTX is excreted by the renal system; thus MTX associated nephrotoxicity is common among patients taking MTX. Fortunately, the resolution usually occurs after discontinuation of therapy and salvage treatment with high-dose corticosteroids [79]. Therefore, to achieve treatment with less side effects, the appropriate route of administration and dose of MTX are necessary. During the treatment, monitoring of patients' general condition matters.

Adverse effects of intravitreal injections of MTX occur only within the eye, including hyperemia, keratopathy, cataract, iridocyclitis, vitreous hemorrhage, retinal detachment, maculopathy, and endophthalmitis [80].

Splitting doses of MTX, rather than intravenous administration, is a new attempt to avoid MTX associated side effects. MTX is split and given twice or thrice in a week to achieve higher bioavailability and better clinical response 
[81, 82], thus providing us with a novel method of oral administration of MTX with less adverse effects.

5.2. Is Low-Dose MTX Safer? Based on clinical cases observation, side effects which can lead to discontinuation of MTX are rare during the typical ophthalmology treatment because of the lower dose of MTX required [30]. The application of low-dose MTX regimen has also become one of the main therapies of a variety of immune-mediated diseases because of its efficacy and an acceptable safety profile, as most low-dose MTX associated toxicity has been described in case reports and relatively small case series [30].

However, although well-tolerated and mostly reversible, even a low-dose regimen of MTX can result in clinically significant toxicity with substantial death rates (about 25\% according to Kivity's cohort study) [30]. The low-dose MTX associated severe adverse effects include major central nervous system complications [83], mucositis, pulmonary involvement, hepatotoxicity [84], and myelosuppression.

5.3. Is MTX Safe to the Pregnant and Fetuses? As one of the lipid-soluble and low molecular weight drugs, MTX could be readily transferred across the placental membrane during pregnancy and adversely affect the fetus [85]. In addition, MTX might take longer time for elimination in fetal tissues [86].

Regarding pharmacogenetics, mutations caused by MTX lead to severe decrease of the expression of folate and nucleobase enzymes, which are critical for cellular homeostasis [87]. In practice, MTX affected formation of the blastocyst and caused dysmorphic features and neurologic defects in early pregnancy, leading to malformations in some cases [88]. Multiple congenital abnormalities have been observed after weekly MTX treatments at a $10 \mathrm{mg}$ dose during the first 3 months of pregnancy [89], even fetal death [85]. Verberne et al. had reviewed cases of congenital anomalies after in utero exposure to MTX and proved that some congenital anomalies such as microcephaly, craniosynostosis, tetralogy of Fallot, pulmonary valve atresia, limb reduction defects, and syndactyly were truly part of the "fetal methotrexate syndrome" [90]. Administration of MTX in childhood might also cause manifestations including visual defect [91] and Smith-Magenis syndrome [43] among patients with specific mutations. Thus, special care should be taken with pregnant patients and children in particular.

5.4. The Risk Factors of MTX Associated Side Effects. The most common risk facts of MTX induced adverse effects are advanced age (age $>75$ years) and underlying disease including renal and/or hepatic insufficiency and lung disease, especially patients with chronic hepatitis $\mathrm{B}$ and diabetes mellitus [92-96]. Patients with a history of alcohol intake might have a greater risk of liver fibrosis and hepatotoxicity caused by MTX administration, with $>100 \mathrm{~g}$ alcohol consumption per week [97]. Also, preexisting hypoalbuminemia and past use of any of the DMARDs and proton-pump inhibitors have been described in studies to increase the incidence of MTX induced side effects [92, 94]. Moreover, taking drugs that may interact with MTX at the same time might also be dangerous; these drugs include salicylates, cotrimoxazole, chloramphenicol, sulfonamides, cyclosporine, and pyrimethamine [96]. Although no significant protective effect of folate supplementation on MTX related toxicity has been found [98], the folate deficiency is another reason for the side effects, based on clinical cases [30]. Heidari et al. found that MTX administration elevated kidney ROS levels, decreased tissue antioxidant capacity, increased lipid peroxidation, and depleted renal glutathione stores. Their research data indicate that MTX caused tissue damage and organ dysfunction through oxidative stress. Therefore, they proposed that patients with preexisting mitochondrial defects might be vulnerable to MTX induced renal injury [99].

The use of high-dose MTX (HD-MTX) is also the risk factor of adverse effects. MTX induced liver fibrosis is more likely to become morphologically evident with high $\mathrm{cu}-$ mulative doses, possibly largely exceeding 3000 to $4000 \mathrm{mg}$ [97, 100]; and the side effects caused by omeprazole use in the past were found in cancer patients receiving HD-MTX treatment [94].

The distribution of MTX in vivo also plays a role in MTX related side effects. As MTX tends to accumulate in the extravascular compartment, patients with pleural effusion, ascites, and massive edema should get extra caution, due to the risk of toxicity from reabsorption of extravascular fluid [101].

Another noteworthy risk factor is UV. UV recall phenomenon, also known as MTX associated UV reactivation, has been reported $[102,103]$. It is reactivity of sunburn areas within 3 to 10 days of the treatment with MTX $[103,104]$. According to Adams and associates, this phenomenon might be due to the immune response by uncontrolled sunburn induced inflammation released by MTX [104]. Patients who previously suffered sunburns deserve more detailed monitoring when methotrexate is needed.

5.5. Is Folate Supplementation Necessary for Ophthalmic Patients? To prevent MTX associated side effects, it is common to take folate [as either folic acid (FA) or folinic acid (FLA)] in clinic $[46,105,106]$. However, there is no consistent and evidence-based guideline for folate supplementation in ophthalmic patients.

Folate and folic acid play significant roles in the de novo synthesis of purines and thymidylate, which are required for DNA replication and repair [96]. Funk and associates found a significant reduction of circulating folate concentrations in $47 \%$ of patients receiving MTX treatment [107]. Patients treated with high-dose MTX (HD-MTX) got routine folate supplementation to reduce HD-MTX associated side effects [108-110]. After a systematic literature review of HD-MTX therapy and folate supplementation, Van der Beek et al. [111] found lower incidence of MTX associated adverse effects in regimens with higher cumulative doses and earlier administration of folate supplementation, in similar HDMTX dosage studies. Folate supplementation in patients with low-dose methotrexate is also being studied. Ortiz et al. [105] had proved the protective effect of folate 
supplementation by conducting a Cochrane review including more than 600 patients taking low-dose MTX. Until now, folate supplementation had been proved to prevent and improve MTX associated effects including gastrointestinal, respiratory, and neurologic side effects $[96,112]$. Mori et al. supported the protective effect by demonstrating that patients treated with low-dose MTX without folate supplements were significantly associated with the development of myelosuppression and pancytopenia [113].

However, Arabelovic and associates' preliminary study showed a significant increase of MTX dose needed [114], since folic acid fortification enriched cereal grain products were fully implemented in the USA and Canada [115]. This conveyed a message to us that high dose of folate supplementation might have influence on the efficacy of MTX.

Al-Dabagh et al. found that the reduction in efficacy of MTX cannot be ignored while folate supplementation did make a significant reduction in associated adverse effects [116]. Salim et al. declared the decreasing influence between the anti-inflammatory effect of MTX and folate supplementation, by carrying out a double-blind clinical trial [117]. Chladek et al. had conducted an open-label, two-way crossover study, supporting the opinion above [118]. Additionally, because of the unequal distribution of folic acid and MTX in organs and tissues [119], MTX discontinuation is more common for some MTX associated side effects in ophthalmic clinic [112], rather than higher dosage of folate supplementation.

There are no ophthalmic studies to demonstrate the protective effects of folic acid supplementation. Thus, although the folate supplementation is widely used among patients treated with low-dose MTX $[120,121]$, the necessity and standardized dosage of folate supplementation in specific patients [122], as well as the MTX-folate interaction, still warrant further studies.

\section{Discussion}

Methotrexate, as one of the alternative pharmacological steroid-sparing immunosuppressive agents, is becoming more and more popular as the preferred treatment in several autoimmune conditions requiring long-term immunosuppression [123]. Low-dose MTX has anti-inflammatory and immunomodulatory properties by increasing levels of intracellular and extracellular adenosine [124], which is the foundation of ophthalmic MTX treatment. The standardized and recommended administration of ophthalmic MTX treatment is once a week, starting with a dose of $7.5 \mathrm{mg}$ and escalating every 4 to 8 weeks up to $25-30 \mathrm{mg} /$ week when necessary $[125,126]$. In patients with insufficient response to MTX alone, cyclosporin with or without azathioprine was added [127].

To avoid side effects, split doses of MTX administration and folate supplementation are gradually being used in ophthalmic clinic. Prescription of 5 to $10 \mathrm{mg}$ of folate supplementation has a significant role in MTX safety [128], but the higher dosage is less applied, even with higher dose of MTX [129]. Prophylactic folate supplementation is not necessary in most patients [130]. There is also research to convey that $0.5 \mathrm{ml} / 100 \mathrm{~g}$ or above dosage of fish oil is as effective as folinic acid in therapeutic potential in preventing bone loss during MTX chemotherapy [131]. For some resistant and/or mortal adverse effects, the discontinuation of MTX will work instantly.

With the increasing long-term use of MTX, it is important to monitor patients' blood examination results, including blood routine and liver and renal functions. As pancytopenia can be a late manifestation [98], elevation of urea, creatinine, aminotransferases, and albumin as well as electrolytes disturbances may result in MTX associated liver and renal side effects [99]. Plasma MTX level is not a reliable predictor for adverse events in MTX therapy [132]. On the contrary, circulating folate levels and folate polyglutamate distribution change sensitively with MTX exposure and exogenous folate supply [133] and could be used as a biomarker of MTX efficacy [107]. It should be noted that as erythrocytes have a half-life of approximately 120 days, the results of blood examinations might reflect both pretreatment and posttreatment status, which need to be analyzed carefully [99].

Numerous studies had been conducted to prove that MTX could be used as a well-tolerated, safe, and effective first-line treatment. Hence, the MTX administration should not continue to be stigmatized as a "cancer drug," or to be discouraged because of associated adverse effects. Contrarily, the indication and the routes of administration are about to gradually widen.

\section{Conflicts of Interest}

The authors declare that they have no conflicts of interest.

\section{References}

[1] R. Q. H. Kloos, R. Pieters, C. van den Bos et al., "The effect of asparaginase therapy on methotrexate toxicity and efficacy in children with acute lymphoblastic leukemia," Leukemia \& Lymphoma, vol. 60, no. 12, pp. 3002-3010, 2019.

[2] R. K. Bath, N. K. Brar, F. A. Forouhar, and G. Y. Wu, "A review of methotrexate-associated hepatotoxicity," Journal of Digestive Diseases, vol. 15, no. 10, pp. 517-524, 2014.

[3] W. Wang, H. Zhou, and L. Liu, "Side effects of methotrexate therapy for rheumatoid arthritis: a systematic review," European Journal of Medicinal Chemistry, vol. 158, pp. 502-516, 2018.

[4] J. Smolen and R. Landewé, "EULAR recommendations for the management of rheumatoid arthritis with synthetic and biological disease-modifying antirheumatic drugs: 2013 update," Annals of the Rheumatic Diseases, vol. 73, no. 3, pp. 492-509, 2014.

[5] J. A. Singh, K. G. Saag, S. L. Bridges et al., "2015 American college of rheumatology guideline for the treatment of rheumatoid arthritis," Arthritis \& Rheumatology, vol. 68, no. 1, pp. 1-26, 2016.

[6] M. Holdhoff, P. Ambady, A. Abdelaziz et al., "High-dose methotrexate with or without rituximab in newly diagnosed primary CNS lymphoma," Neurology, vol. 83, no. 3, pp. 235-239, 2014.

[7] J. Pe'er, J. M. Rowe, S. Frenkel, and E. J. Dann, “Testicular lymphoma, intraocular(vitreoretinal) lymphoma, and brain lymphoma: involvement of three immunoprivileged sites in 
one patient," American Journal of Hematology, vol. 85, no. 8, pp. 631-633, 2010.

[8] S. Gangaputra, C. W. Newcomb, T. L. Liesegang et al., "Systemic immunosuppressive therapy for eye diseases cohort study: methotrexate for ocular inflammatory diseases," Ophthalmology, vol. 116, no. 11, pp. 2188-2198, 2009.

[9] P. W. Hardwig, J. S. Pulido, J. C. Erie, K. H. Baratz, and H. Buettner, "Intraocular methotrexate in ocular diseases other than primary central nervous system lymphoma," American Journal of Ophthalmology, vol. 142, no. 5, pp. 883-885, 2006.

[10] E. Esterberg and N. R. Acharya, "Corticosteroid-sparing therapy: practice patterns among uveitis specialists," Journal of Ophthalmic Inflammation and Infection, vol. 2, no. 1, pp. 21-28, 2012.

[11] K. Durrani, F. R. Zakka, M. Ahmed, M. Memon, S. S. Siddique, and C. S. Foster, "Systemic therapy with conventional and novel immunomodulatory agents for ocular inflammatory disease," Survey of Ophthalmology, vol. 56, no. 6, pp. 474-510, 2011.

[12] S. S. Gangaputra, C. W. Newcomb, M. M. Joffe et al., "Comparison between methotrexate and mycophenolate mofetil monotherapy for the control of noninfectious ocular inflammatory diseases," American Journal of Ophthalmology, vol. 208, pp. 68-75, 2019.

[13] V. K. Ayuso, E. L. van de Winkel, A. Rothova, and J. Helena de Boer, "Relapse rate of uveitis post-methotrexate treatment in juvenile idiopathic arthritis," American Journal of Ophthalmology, vol. 151, no. 2, pp. 217-222, 2011.

[14] S. R. Rathinam, M. Babu, R. Thundikandy et al., "A randomized clinical trial comparing methotrexate and mycophenolate mofetil for noninfectious uveitis," Ophthalmology, vol. 121, no. 10, pp. 1863-1870, 2014.

[15] A. Galor, D. A. Jabs, H. A. Leder et al., "Comparison of antimetabolite drugs as corticosteroid-sparing therapy for noninfectious ocular inflammation," Ophthalmology, vol. 115, no. 10, pp. 1826-1832, 2008.

[16] M. D. de Smet, V. S. Vancs, D. Kohler, D. Solomon, and C. C. Chan, "Intravitreal chemotherapy for the treatment of recurrent intraocular lymphoma," British Journal of Ophthalmology, vol. 83, no. 4, pp. 448-451, 1999.

[17] E. Kim, C. Kim, J. Lee, and Y. Cho, "A case of primary intraocular lymphoma treated by intravitreal methotrexate," Korean Journal of Ophthalmology, vol. 23, no. 3, pp. 210-214, 2009.

[18] J. Smith, J. T. Rosenbaum, D. J. Wilson et al., "Role of intravitreal methotrexate in the management of primary central nervous system lymphoma with ocular involvement historical image," Ophthalmology, vol. 109, no. 9, pp. 17091716, 2002.

[19] C.-C. Chan and D. J. Wallace, "Intraocular lymphoma: update on diagnosis and management," Cancer Control, vol. 11, no. 5, pp. 285-295, 2004.

[20] K. L. Larkin, U. S. Saboo, G. M. Comer et al., "Use of intravitreal rituximab for treatment of vitreoretinal lymphoma," British Journal of Ophthalmology, vol. 98, no. 1, pp. 99-103, 2014.

[21] C. P. Fox, E. H. Phillips, J. Smith et al., "Guidelines for the diagnosis and management of primary central nervous system diffuse large B-cell lymphoma," British Journal of Haematology, vol. 184, no. 3, pp. 348-363, 2019.

[22] A. Sadaka, R. Sisk, J. Osher, O. Toygar, M. Duncan, and C. Riemann, "Intravitreal methotrexate infusion for proliferative vitreoretinopathy," Clinical Ophthalmology, vol. 10, pp. 1811-1817, 2016.

[23] N. G. Lambert, D. J. Wilson, D. M. Albert, and W. D. Chamberlain, "Intravitreal methotrexate for recurrent epithelial downgrowth," JAMA Ophthalmology, vol. 137, no. 9, p. 1082, 2019.

[24] A. M. Joussen, F. E. Kruse, H.-E. Völcker, and B. Kirchhof, "Topical application of methotrexate for inhibition of corneal angiogenesis," Graefe's Archive for Clinical and Experimental Ophthalmology, vol. 237, no. 11, pp. 920-927, 1999.

[25] S. K. Kurup, C. Gee, and C. M. Greven, "Intravitreal methotrexate in therapeutically resistant exudative age-related macular degeneration," Acta Ophthalmologica, vol. 88, no. 4, pp. e145-e146, 2009.

[26] H. E. M. Khalil, H. A. Raafat, N. A. Azab, H. E. Haroun, and H. A. Elgendi, "The role of intraocular methotrexate in the management of uveitis and posterior segment involvement in Behçet's disease patients," The Egyptian Rheumatologist, vol. 37, no. 3, pp. 113-118, 2015

[27] S. R. J. Taylor, A. Banker, A. Schlaen et al., "Intraocular methotrexate can induce extended remission in some patients in noninfectious uveitis," Retina, vol. 33, no. 10, pp. 2149-2154, 2013.

[28] G. Gervasini, S. G. de Murillo, M. Jiménez, M. D. de la Maya, and J. M. Vagace, "Effect of polymorphisms in transporter genes on dosing, efficacy and toxicity of maintenance therapy in children with acute lymphoblastic leukemia," Gene, vol. 628, pp. 72-77, 2017.

[29] P. Ranganathan and H. L. McLeod, "Methotrexate pharmacogenetics: the first step toward individualized therapy in rheumatoid arthritis," Arthritis \& Rheumatism, vol. 54, no. 5, pp. 1366-1377, 2006

[30] S. Kivity, Y. Zafrir, R. Loebstein, R. Pauzner, M. Mouallem, and $\mathrm{H}$. Mayan, "Clinical characteristics and risk factors for low dose methotrexate toxicity: a cohort of 28 patients," Autoimmunity Reviews, vol. 13, no. 11, pp. 1109-1113, 2014.

[31] J. R. Whetstine, T. L. Witt, and L. H. Matherly, "The human reduced folate carrier gene is regulated by the AP2 and SP1 transcription factor families and a functional 61-base pair polymorphism," Journal of Biological Chemistry, vol. 277, no. 46, pp. 43873-43880, 2002.

[32] C. Laverdiere, S. Chiasson, I. Costea, A. Moghrabi, and M. Krajinovic, "Polymorphism $\mathrm{G}_{80} \mathrm{~A}$ in the reduced folate carrier gene and its relationship to methotrexate plasma levels and outcome of childhood acute lymphoblastic leukemia," Blood, vol. 100, no. 10, pp. 3832-3834, 2002.

[33] T. Dervieux, J. Kremer, D. O. Lein et al., "Contribution of common polymorphisms in reduced folate carrier and ??-glutamylhydrolase to methotrexate polyglutamate levels in patients with rheumatoid arthritis," Pharmacogenetics, vol. 14, no. 11, pp. 733-739, 2004.

[34] T. Dervieux, D. O. Lein, M. Walsh et al., "Single nucleotide polymorphisms (SNPs) in the folate/purine synthesis pathway predict methotrexate's effects in rheumatoid arthritis," Arthritis Rheum, vol. 48, no. 9, p. S438, 2003.

[35] A. Chango, N. Emery-Fillon, D. S. Rosenblatt et al., "A polymorphism (80G->A) in the reduced folate carrier gene and its associations with folate status and homocysteinemia," Molecular Genetics and Metabolism, vol. 70, no. 4, pp. 310-315, 2000.

[36] J. R. Whetstine, A. J. Gifford, M. Norris et al., "Single nucleotide polymorphisms in the human reduced folate carrier: characterization of a high-frequency G/A variant at position 
80 and transport properties of the $\mathrm{His}^{27}$ and $\mathrm{Arg}^{27}$ carriers," Clinical Cancer Research, vol. 7, pp. 3416-3422, 2001.

[37] M. D. Norris, D. D. Graaf, M. Haber et al., "Involvement ofMDR1 P-glycoprotein in multifactorial resistance to methotrexate," International Journal of Cancer, vol. 65, no. 5, pp. 613-619, 1996.

[38] S. Hoffmeyer, O. Burk, O. von Richter et al., "Functional polymorphisms of the human multidrug-resistance gene: multiple sequence variations and correlation of one allele with P-glycoprotein expression and activity in vivo," Proceedings of the National Academy of Sciences, vol. 97, no. 7, pp. 3473-3478, 2000.

[39] P. Bohanec Grabar, D. Logar, B. Lestan, and V. Dolžan, "Genetic determinants of methotrexate toxicity in rheumatoid arthritis patients: a study of polymorphisms affecting methotrexate transport and folate metabolism," European Journal of Clinical Pharmacology, vol. 64, no. 11, pp. 10571068, 2008.

[40] R. E. Windsor, S. J. Strauss, C. Kallis, N. E. Wood, and J. S. Whelan, "Germline genetic polymorphisms may influence chemotherapy response and disease outcome in osteosarcoma: a pilot study," Cancer, vol. 118, no. 7, pp. 1856-1867, 2012.

[41] S. L. Hider, I. N. Bruce, and W. Thomson, "The pharmacogenetics of methotrexate," Rheumatology, vol. 46, no. 10, pp. 1520-1524, 2007.

[42] L. Lambrecht, C. Sleurs, V. Labarque et al., "The role of the MTHFR C677T polymorphism in methotrexate-induced toxicity in pediatric osteosarcoma patients," Pharmacogenomics, vol. 18, no. 8, pp. 787-795, 2017.

[43] M. H. Weisman, D. E. Furst, T. Dervieux et al., "Risk genotypes in folate-dependent enzymes and their association with methotrexate-related side effects in rheumatoid arthritis," Arthritis \& Rheumatism, vol. 54, no. 2, pp. 607-612, 2006.

[44] L. M. Berkani, F. Rahal, I. Allam, S. M. Benani, A. Laadjouz, and R. Djidjik, "Association of MTHFR C677T and A1298C gene polymorphisms with methotrexate efficiency and toxicity in algerian rheumatoid arthritis patient," Heliyon, vol. 3, no. 11, Article ID e00467, 2017.

[45] L. Stamp, R. Roberts, M. Kennedy, M. Barclay, J. O'Donnell, and P. Chapman, "The use of low dose methotrexate in rheumatoid arthritis-are we entering a new era of therapeutic drug monitoring and pharmacogenomics?" Biomedicine \& Pharmacotherapy, vol. 60, no. 10, pp. 678-687, 2006.

[46] L. F. Restrepo, R. Giraldo, J. Londoño et al., "Pharmacogenetics of methotrexate in rheumatoid arthritis: a systematic review," Revista Colombiana de Reumatología (English Edition), vol. 23, no. 2, pp. 102-114, 2016.

[47] V. Chandran, F. Siannis, P. Rahman, F. J. Pellett, V. T. Farewell, and D. D. Gladman, "Folate pathway enzyme gene polymorphisms and the efficacy and toxicity of methotrexate in psoriatic arthritis," The Journal of Rheumatology, vol. 37, no. 7, pp. 1508-1512, 2010.

[48] S. Indhumathi, M. Rajappa, L. Chandrashekar, P. H. Ananthanarayanan, D. M. Thappa, and V. S. Negi, "Pharmacogenetic markers to predict the clinical response to methotrexate in south Indian Tamil patients with psoriasis," European Journal of Clinical Pharmacology, vol. 73, no. 8, pp. 965-971, 2017.

[49] Y. H. Lee and S.-C. Bae, "Association of the ATIC 347 C/G polymorphism with responsiveness to and toxicity of methotrexate in rheumatoid arthritis: a meta-analysis,"
Rheumatology International, vol. 36, no. 11, pp. 1591-1599, 2016.

[50] N. Muralidharan, C. M. Mariaselvam, V. K. Jain, R. Gulati, and V. S. Negi, "ATIC 347C > G gene polymorphism may be associated with methotrexate-induced adverse events in south Indian Tamil rheumatoid arthritis," Pharmacogenomics, vol. 17, no. 3, pp. 241-248, 2016.

[51] Q. Qiu, J. Huang, X. Shu, H. Fan, Y. Zhou, and C. Xiao, "Polymorphisms and pharmacogenomics for the clinical efficacy of methotrexate in patients with rheumatoid arthritis: a systematic review and meta-analysis," Scientific Reports, vol. 7, no. 1, Article ID 44015, 2017.

[52] A. Lima, V. Seabra, M. Bernardes, R. Azevedo, and R. Medeiros, "Role of key TYMS polymorphisms on methotrexate therapeutic outcome in Portuguese rheumatoid arthritis patients," PLoS One, vol. 9, no. 10, Article ID e108165, 2014.

[53] B. Jekic, L. Lukovic, V. Bunjevacki et al., "Association of the TYMS 3G/3G genotype with poor response and GGH 354GG genotype with the bone marrow toxicity of the methotrexate in RA patients," European Journal of Clinical Pharmacology, vol. 69, no. 3, pp. 377-383, 2013.

[54] S. Tavakolpour, M. Darvishi, and M. Ghasemiadl, "Pharmacogenetics: a strategy for personalized medicine for autoimmune diseases," Clinical Genetics, vol. 93, no. 3, pp. 481-497, 2018.

[55] R. B. Warren, R. L. Smith, E. Campalani et al., "Outcomes of methotrexate therapy for psoriasis and relationship to genetic polymorphisms," British Journal of Dermatology, vol. 160, no. 2, pp. 438-441, 2009.

[56] X. Li, A. Zhang, H. Sun et al., "Metabolic characterization and pathway analysis of berberine protects against prostate cancer," Oncotarget, vol. 8, no. 39, pp. 65022-65041, 2017.

[57] K. Albrecht and U. Müller-Ladner, "Side effects and management of side effects of methotrexate in rheumatoid arthritis," Clinical and Experimental Rheumatology, vol. 28, pp. S95-S101, 2010.

[58] S. M. Attar, "Adverse effects of low dose methotrexate in rheumatoid arthritis patients. A hospital-based study," Saudi Medical Journal, vol. 31, no. 8, pp. 909-915, 2010.

[59] A. M. Buhroo and A. N. Baba, "Adverse effects of low-dose methotrexate in patients with rheumatoid arthritis," Indian Journal of Physical Medicine and Rehabilitation, vol. 17, pp. 21-25, 2006.

[60] M. A. Ramírez Huaranga, E. Bencosme de Mendez, J. L. Cuadra Díaz, J. Lázaro Polo, and C. Bujalance Cabrera, "Neumonitis por citomegalovirus durante el tratamiento crónico con metotrexato," Reumatología Clínica (English Edition), vol. 10, no. 5, pp. 328-330, 2014.

[61] R. A. Balk, Methotrexate-induced Lung Injury, K. R. Flaherty, J. R. Jett, H. Hollingsworth, and D. Savarese, Eds., UpToDate, Waltham, MA, USA, 2013.

[62] E. Campalani, M. Arenas, A. M. Marinaki, C. M. Lewis, J. N. W. N. Barker, and C. H. Smith, "Polymorphisms in folate, pyrimidine, and purine metabolism are associated with efficacy and toxicity of methotrexate in psoriasis," Journal of Investigative Dermatology, vol. 127, no. 8, pp. 1860-1867, 2007.

[63] A. McLean-Tooke, C. Aldridge, S. Waugh, G. P. Spickett, and L. Kay, "Methotrexate, rheumatoid arthritis and infection risk--what is the evidence?" Rheumatology, vol. 48, no. 8, pp. 867-871, 2009.

[64] K. Au, G. Reed, J. R. Curtis et al., "High disease activity is associated with an increased risk of infection in patients with 
rheumatoid arthritis," Annals of the Rheumatic Diseases, vol. 70, no. 5, pp. 785-791, 2011.

[65] T. Borsos, V. C. Dunkel, and J. J. Langone, "Immunoassay of antigens and haptens by inhibition of passive immune hemolysis," Journal of Immunological Methods, vol. 32, no. 2, pp. 105-114, 1980.

[66] D. M. Hansell, D. A. Lynch, H. P. McAdams, and A. B. Alexander, Imaging of Diseases of the Chest, Mosby, Maryland Heights, MO, USA, 2009.

[67] D. J. Naisbitt, M. Pirmohamed, and B. K. Park, "Immunopharmacology of hypersensitivity reactions to drugs," Current Allergy and Asthma Reports, vol. 3, no. 1, pp. 22-29, 2003.

[68] M. Pirmohamed, D. J. Naisbitt, F. Gordon, and B. K. Park, "The danger hypothesis-potential role in idiosyncratic drug reactions," Toxicology, vol. 181-182, pp. 55-63, 2002.

[69] B. Chikura, N. Sathi, and J. Dawson, "Methotrexate induced pneumonitis: a review article," Current Respiratory Medicine Reviews, vol. 5, no. 1, pp. 12-20, 2009.

[70] S. Miyaza, R. Matsuda, M. Nakamura, I. Nakagawa, Y. Motoyama, and H. Nakase, "Intracranial methotrexateassociated lymphoproliferative disorder in rheumatoid arthritis," World Neurosurgery, vol. 130, pp. 138-141, 2019.

[71] M. Harigai, "Lymphoproliferative disorders in patients with rheumatoid arthritis in the era of widespread use of methotrexate: a review of the literature and current perspective," Modern Rheumatology, vol. 28, no. 1, pp. 1-8, 2018.

[72] W.-F. Lai, Y.-P. Chin, C.-W. Liu, and C.-Y. Tsai, "Methotrexate-associated lymphoproliferative disease with multiple pulmonary nodules in a patients with rheumatoid arthritis," BMJ Case Reports, 2017.

[73] S. Makihara, S. Kariya, M. Noujima-Harada et al., "Methotrexate-associated lymphoproliferative disorder with multiple pulmonary nodules and bilateral cervical lymphadenopathy," Auris Nasus Larynx, vol. 46, no. 6, pp. 927-933, 2019.

[74] Y. Hoshida, J. X. Xu, S. Fujita et al., "Lymphoproliferative disorders in rheumatoid arthritis: clinicopathological analysis of 76 cases in relation to methotrexate medication," The Journal of Rheumatology, vol. 34, no. 2, pp. 322-331, 2007.

[75] S. H. Swerdlow, E. Compo, H. Stein et al., WHO Classification of Tumours of Haematopoietic and Lymphoid Tissues, World Health Organization, Geneva, Switzerland, 4th edition, 2008.

[76] R. Rizzi, P. Curci, M. Delia et al., "Spontaneous remission of "methotrexate-associated lymphoproliferative disorders" after discontinuation of immunosuppressive treatment for autoimmune disease," Medical Oncology, vol. 26, no. 1, pp. 1-9, 2009.

[77] A. Zhang, H. Sun, and X. Wang, "Potentiating therapeutic effects by enhancing synergism based on active constituents from traditional medicine," Phytotherapy Research, vol. 28, no. 4, pp. 526-533, 2014.

[78] M. Bulatovi Ćalasan, O. F. C. van den Bosch, M. C. W. Creemers et al., "Prevalence of methotrexate intolerance in rheumatoid arthritis and psoriatic arthritis," Arthritis Research \& Therapy, vol. 15, no. 6, p. R217, 2013.

[79] A. Lima, M. Bernardes, H. Sousa et al., "SLC19A180G allele as a biomarker of methotrexate-related gastrointestinal toxicity in Portuguese rheumatoid arthritis patients," Pharmacogenomics, vol. 15, no. 6, pp. 807-820, 2014.

[80] Y.-C. Huang and J.-R. Jou, "Intravitreal injections of methotrexate in treatment of primary central nervous system lymphoma with intraocular involvement," The Kaohsiung Journal of Medical Sciences, vol. 32, no. 12, pp. 638-639, 2016.

[81] P. Dhaon, S. K. Das, R. Srivastava, G. Agarwal, and A. Asthana, "Oral methotrexate in split dose weekly versus oral or parenteral methotrexate once weekly in rheumatoid arthritis: a short-term study," International Journal of Rheumatic Diseases, vol. 21, no. 5, pp. 1010-1017, 2018.

[82] M. Hoekstra, C. Haagsma, C. Neef et al., "Splitting high dose methotrexate improves bioavailability: a phar-macokinetic study in patients of rheumatoid arthritis," Clinical Therapeutics, vol. 36, pp. 427-435, 2014.

[83] I. Gonzalez-Suarez, M. J. Aguilar-Amat, M. Trigueros, A. M. Borobia, A. Cruz, and J. Arpa, "Leukoencephalopathy due to oral methotrexate," Cerebellum, vol. 13, no. 1, pp. 178-183, 2014.

[84] P. L. Valentino, P. C. Church, P. S. Shah et al., "Hepatotoxicity caused by methotrexate therapy in children with inflammatory bowel disease: a systematic review and metaanalysis," Inflammatory Bowel Diseases, vol. 20, no. 1, pp. 47-59, 2014.

[85] N. Calvey, "Adverse drug reactions," Anaesthesia \& Intensive Care Medicine, vol. 9, no. 7, pp. 319-323, 2008.

[86] B. Brenner, I. Avivi, and M. Lishner, "Haematological cancers in pregnancy," The Lancet, vol. 379, no. 9815, pp. 580-587, 2012.

[87] D. E. Furst and J. M. Kremer, "Methotrexate in rheumatoid arthritis," Arthritis \& Rheumatism, vol. 31, no. 3, pp. 305-314, 1988.

[88] R. Hastie, E. Lim, P. Sluka et al., "Vinorelbine potently induces placental cell death, does not harm fertility and is a potential treatment for ectopic pregnancy," EBioMedicine, vol. 29, pp. 166-176, 2017.

[89] L. M. Buckley, C. A. Bullaboy, L. Leichtman, and M. Marquez, "Multiple congenital anomalies associated with weekly low-dose methotrexate treatment of the mother," Arthritis \& Rheumatism, vol. 40, no. 5, pp. 971-973, 1997.

[90] E. A. Verberne, E. de Haan, J. P. van Tintelen, D. Lindhout, and M. M. van Haelst, "Fetal methotrexate syndrome: a systematic review of case reports," Reproductive Toxicology, vol. 87, pp. 125-139, 2019.

[91] S. Marie, B. Heron, P. Bitoun, T. Timmerman, G. Van den Berghe, and M.-F. Vincent, "AICA-ribosiduria: a novel, neurologically devastating inborn error of purine biosynthesis caused by mutation of ATIC," The American Journal of Human Genetics, vol. 74, no. 6, pp. 1276-1281, 2004.

[92] P. Vaideeswar, N. Gogtay, U. Thatte, S. Yadav, and S. Kannan, "Methotrexate-induced pneumonitis and myocarditis," Indian Journal of Pathology and Microbiology, vol. 57, no. 1, pp. 152-153, 2014.

[93] Y. Arakawa, A. Arakawa, S. Vural, R. Mahajan, and J. C. Prinz, "Renal clearance and intracellular half-life essentially determine methotrexate toxicity: a case series," JAAD Case Reports, vol. 5, no. 1, pp. 98-100, 2019.

[94] F. Ranchon, N. Vantard, A. Gouraud et al., "Suspicion of drug-drug interaction between high-dose methotrexate and proton pump inhibitors: a case report-should the practice be changed?" Chemotherapy, vol. 57, no. 3, pp. 225-229, 2011.

[95] A. V. Thatishetty, N. Agresti, and C. B. O’Brien, "Chemotherapy-induced hepatotoxicity," Clinics in Liver Disease, vol. 17, no. 4, pp. 671-686, 2013.

[96] W. Baran, A. Batycka-Baran, M. Zychowska, A. Bieniek, and J. C. Szepietowski, "Folate supplementation reduces the side 
effects of methotrexate therapy for psoriasis," Expert Opinion on Drug Safety, vol. 13, no. 8, pp. 1015-1021, 2014.

[97] D. Pathirana, A. Ormerod, P. Saiag et al., "European S3guidelines on the systemic treatment of psoriasis vulgaris," Journal of the European Academy of Dermatology and Venereology, vol. 23, pp. 1-70, 2009.

[98] A. Y. N. Lim, K. Gaffney, and D. G. I. Scott, "Methotrexateinduced pancytopenia: serious and under-reported? Our experience of 25 cases in 5 years," Rheumatology, vol. 44, no. 8, pp. 1051-1055, 2005.

[99] R. Heidari, A. Ahmadi, H. Mohammadi, M. M. Ommati, N. Azarpira, and H. Niknahad, "Mitochondrial dysfunction and oxidative stress are involved in the mechanism of methotrexate-induced renal injury and electrolytes imbalance," Biomedicine \& Pharmacotherapy, vol. 107, pp. 834840, 2018.

[100] U. Arena, C. Stasi, A. Mannoni et al., "Liver stiffness correlates with methotrexate cumulative dose in patients with rheumatoid arthritis," Digestive and Liver Disease, vol. 44, no. 2, pp. 149-153, 2012.

[101] L. Puig, "Methotrexate: new therapeutic approaches," Actas Dermo-Sifiliográficas (English Edition), vol. 105, no. 6, pp. 583-589, 2014.

[102] K. L. Goldfeder, J. M. Levin, K. A. Katz, L. E. Clarke, A. W. Loren, and W. D. James, "Ultraviolet recall reaction after total body irradiation, etoposide, and methotrexate therapy," Journal of the American Academy of Dermatology, vol. 56, no. 3, pp. 494-499, 2007.

[103] W. Lapolla, B. A. Yentzer, S. R. Feldman et al., "A review of phototherapy protocols for psoriasis treatment," Journal of the American Academy of Dermatology, vol. 64, no. 5, pp. 936-949, 2011.

[104] J. Yankura, N. Saddic, C. R. Jones, and D. R. Adams, "Methotrexate sodium-associated UV reactivation in a patient with acute lymphoblastic leukemia," Cutis, vol. 89, no. 5, pp. 233-236, 2012.

[105] Z. Ortiz, B. Shea, M. E. Suarez-Almazor, D. Moher, G. A. Wells, and P. Tugwell, "Folic acid and folinic acid for reducing side effects in patients receiving methotrexate for rheumatoid arthritis," Cochrane Database of Systematic Reviews, vol. 5, Article ID CD000951, 2013.

[106] C. J. Lucas, S. B. Dimmitt, and J. H. Martin, "Optimising lowdose methotrexate for rheumatoid arthritis-a review," British Journal of Clinical Pharmacology, vol. 85, no. 10, pp. 22282234, 2019.

[107] R. S. Funk, L. van Haandel, J. Steven Leeder, and M. L. Becher, "Folate depletion and increased glutamation in juvenile idiopathic arthritis patients treated with methotrexate," Arthritis \& Rheumatology, vol. 66, no. 12, pp. 3476-3485, 2014.

[108] M. A. H. den Hoed, E. Lopez-Lopez, M. L. te Winkel et al., "Genetic and metabolic determinants of methotrexate-induced mucositis in pediatric acute lymphoblastic leukemia," The Pharmacogenomics Journal, vol. 15, no. 3, pp. 248-254, 2015.

[109] P. Wennerstrand, L.-G. Mårtensson, S. Söderhäll, A. Zimdahl, and M. L. Appell, "Methotrexate binds to recombinant thiopurine S-methyltransferase and inhibits enzyme activity after high-dose infusions in childhood leukaemia," European Journal of Clinical Pharmacology, vol. 69, no. 9, pp. 1641-1649, 2013.

[110] I. J. Cohen and J. E. Wolff, "How long can folinic acid rescue be delayed after high-dose methotrexate without toxicity?" Pediatric Blood \& Cancer, vol. 61, no. 1, pp. 7-10, 2013.
[111] J. Van der Beek, N. Oosterom, R. Pieters, R. de Jonge, M. van den Heuvel-Eibrink, and S. Heil, "The effect of leucovorin rescue therapy on methotrexate-induced oral mucositis in the treatment of paediatric ALL: a systematic review," Critical Reviews in Oncology/Hematology, vol. 142, pp. 1-8, 2019.

[112] M. Kawami, R. Harabayashi, R. Harada, Y. Yamagami, R. Yumoto, and M. Takano, "Folic acid prevents methotrexate-induced epithelial-mesenchymal transition via suppression of secreted factors from the human alveolar epithelial cell line A549," Biochemical and Biophysical Research Communications, vol. 497, no. 1, pp. 457-463, 2018.

[113] S. Mori, M. Hidaka, T. Kawakita et al., "Factors associated with myelosuppression related to low-dose methotrexate therapy for inflammatory," Rheumatic Diseases, vol. 11, Article ID e0154744, 2016.

[114] S. Arabelovic, G. Sam, G. E. Dallal, P. F. Jacques, I. H. Rosenberg, and R. Roubenoff, "Preliminary evidence shows that folic acid fortification of the food supply is associated with higher methotrexate dosing in patients with rheumatoid arthritis," Journal of the American College of Nutrition, vol. 26, no. 5, pp. 453-455, 2007.

[115] G. Amarlilyo, O. J. Rullo, D. K. McCurdy, J. M. P. Woo, and D. E. Furst, "Folate usage in MTX-treated juvenile idiopathic arthritis (JIA) patients is inconsistent and highly variable," Rheumatology International, vol. 33, no. 9, pp. 2437-2440, 2013.

[116] A. Al-Dabagh, S. A. Davis, M. A. Kinney, K. Huang, and S. R. Feldman, "The effect of folate supplementation on methotrexate efficacy and toxicity in psoriasis patients and folic acid use by dermatologists in the USA," American Journal of Clinical Dermatology, vol. 14, no. 3, pp. 155-161, 2013.

[117] A. Salim, E. Tan, A. Ilchyshyn, and J. Berth-Jones, "Folic acid supplementation during treatment of psoriasis with methotrexate: a randomized, double-blind, placebo-controlled trial," British Journal of Dermatology, vol. 154, no. 6, pp. 1169-1174, 2006.

[118] J. Chládek, M. Simková, J. Vanecková et al., “The effect of folic acid supplementation on the pharmacokinetics and pharmacodynamics of oral methotrexate during the remission-induction period of treatment for moderate-to-severe plaque psoriasis," European Journal of Clinical Pharmacology, vol. 64, no. 4, pp. 347-355, 2008.

[119] B. D. Jakubovic, A. Donovan, P. M. Webster, and N. H. Shear, "Methotrexate-induced pulmonary toxicity," Canadian Respiratory Journal, vol. 20, no. 3, pp. 153-155, 2013.

[120] I. García Cárdaba, J. Antón, J. C. López Robledillo et al., "Recomendaciones para el uso de metotrexato en pacientes con artritis idiopática juvenil," Anales de Pediatría, vol. 84, no. 3, pp. 177.e1-177 e8, 2016.

[121] G. Ferrara, G. Mastrangelo, P. Barone et al., "Methotrexate in juvenile idiopathic arthritis: advice and recommendations from the MARAJIA expert consensus meeting," Pediatric Rheumatology, vol. 16, no. 1, p. 46, 2018.

[122] E. Barral Mena, L. M. García Cárdaba, A. Canet Tarrés, E. Enríquez Merayo, A. Cruz Utrilla, and J. de Inocencio Arocena, "Metotrexato en artritis idiopática juvenil: efectos adversos y factores asociados," Anales de Pediatría, vol. 92, no. 3, pp. 124-131, 2020.

[123] Z. Sipkova, E. A. Insull, J. David, H. E. Turner, S. Keren, and J. H. Norris, "Early use of steroid-sparing agents in the inactivation of moderate-to-severe active thyroid eye disease: 
a step-down approach," Clinical Endocrinology, vol. 89, no. 6, pp. 834-839, 2018.

[124] A. N. Malaviya, A. Sharma, D. Agarwal, S. Kapoor, S. Garg, and S. Sawhney, "Low-dose and high-dose methotrexate are two different drugs in practical terms," International Journal of Rheumatic Diseases, vol. 13, no. 4, pp. 288-293, 2010.

[125] D. Wakefield, P. McCluskey, G. Wildner et al., "Inflammatory eye disease: pre-treatment assessment of patients prior to commencing immunosuppressive and biologic therapy: recommendations from an expert committee," Autoimmunity Reviews, vol. 16, no. 3, pp. 213-222, 2017.

[126] M. Hassan, S. Karkhur, J. H. Bae et al., "New therapies in development for the management of non-infectious uveitis: a review," Clinical \& Experimental Ophthalmology, vol. 47, no. 3, pp. 396-417, 2019.

[127] M. J. Weiss and A. J. Hofeldt, "Diagnosis and management of ocular inflammatory disease," in The Columbia Guide to Basic Elements of Eye Care, D. Casper and G. Cioffi, Eds., Springer, Cham, Switzerland, 2019.

[128] E. Dalkilic, B. N. Coskun, B. Yağız, A. N. Tufan, S. Ermurat, and Y. Pehlivan, "Methotrexate intoxication: beyond the adverse events," International Journal of Rheumatic Diseases, vol. 21, no. 8, pp. 1557-1562, 2018.

[129] V. Dhir, A. Sandhu, S. Sharma et al., "Comparison of two different folic acid doses with methotrexate-a randomized controlled trial (FOLVARI Study)," Arthritis Research \& Therapy, vol. 17, no. 1, p. 156, 2015.

[130] G. Tonini, A. Lamberti, I. Guidi, E. Cinotti, and P. Rubegni, "Mucocutaneous ulcers as forerunners of methotrexate toxicity," Dermatologic Therapy, vol. 32, no. 2, Article ID e12823, 2019.

[131] R. R. Nadhanan, C.-M. Fan, Y.-W. Su, P. R. C. Howe, and C. J. Xian, "Fish oil in comparison to folinic acid for protection against adverse effects of methotrexate chemotherapy on bone," Orthopedic Research Society, vol. 32, no. 4, pp. 587-596, 2014.

[132] M. Tsurusawa, M. Gosho, T. Mori et al., "Statistical analysis of relation between plasma methotrexate concentration and toxicity in high-dose methotrexate therapy of childhood non hodgkin lymphoma," Pediatric Blood \& Cancer, vol. 62, no. 2, pp. 279-284, 2015.

[133] R. K. Singh, L. van Haandel, P. Kiptoo, M. L. Becker, T. J. Siahaan, and R. S. Funk, "Methotrexate disposition, antifolate activity and efficacy in the collagen-induced arthritis mouse model," European Journal of Pharmacology, vol. 853, pp. 264-274, 2019. 